\title{
CHANGING PROVISION AND USE OF NEIGHBOURHOOD PUBLIC SPACE IN NEPAL'S KATHMANDU VALLEY
}

\author{
Rajjan Man CHITRAKAR ${ }^{a}$, Douglas C. BAKER ${ }^{b}$, Mirko GUARALDA $^{c}$ \\ a, cSchool of Design, Creative Industries Faculty, Queensland University of Technology, 2 George Street, \\ Brisbane, Queensland 4000, Australia \\ ${ }^{b}$ School of Civil Engineering and Built Environment, Faculty of Science and Engineering, Queensland University \\ of Technology, 2 George Street, Brisbane, Queensland 4000, Australia \\ E-mails: ${ }^{a}$ razn77@hotmail.com and rajjan.chitrakar@qut.edu.au (correspondingauthor);

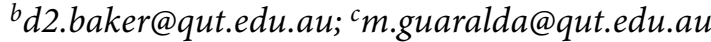

Received 01 August 2016; accepted 20 December 2016

\begin{abstract}
Modern cities have witnessed a significant level of transformation of urban environments, in which the urban neighbourhoods of recent origin have also changed. This paper explores the transformation of public space in contemporary urban neighbourhoods of the Kathmandu Valley in Nepal. It examines the changing provision and use of public space through a case study of three recent neighbourhoods using observations and interviews. The study identifies fundamental differences in the development of public space, suggesting that public spaces are no longer the central elements of new neighbourhoods. Further changes with the provision of public space include the existing spatial configuration of open spaces, the loss of social quality of neighbourhood streets and the rise of alternative public venues. The changing provision of public space has influenced the use with the shifting locations of public activities. There is a growing tendency to use the streets as a public space along with other privately owned public spaces. While a large portion of public space remains underutilised or has been put into an inappropriate use, some new uses of public spaces are also noticed in the changing context.
\end{abstract}

Keywords: new neighbourhoods, neighbourhood public space, provision of public space, use of public space, Kathmandu Valley.

\section{Introduction}

Urban change is a global phenomenon with widespread consequences on urban form and life across different geographical regions. Over the past century, modern cities have witnessed a significant level of transformation of built environments, in which the residential neighbourhoods of recent origin have also changed. Kathmandu Valley, the cultural, economic and political centre of Nepal, has not been immune to the forces of urban change. The valley was exposed to globalisation only in 1951, following the political change; however this change also generated migration from all over the country (Basyal, Khanal 2001; Shah, Pant 2005). This led to rapid growth and transformation of urban landscape in the valley, with the city cores expanding to take the emerging form of a sprawl
(ICIMOD, UNEP, Government of Nepal 2007; Thapa et al. 2008). The transformation became evident by the 1980s, when the growing suburbs started to show a sharp contrast with their traditional counterparts in terms of the urban settings (Adhikari 1998). By now, the Kathmandu Valley has been transformed into an uncontrolled metropolitan sprawl from a planned and compact settlement of the past (KMC/World Bank 2001; Shah, Pant 2005).

The contemporary urban growth of the Kathmandu Valley has not been conducive to the development of public space. Scholars argue that there is a significant loss of public space, due to the rapid and uncontrolled development of most new urban areas (see Adhikari 1998; KMC/World Bank, 2001; Pradhan 2003; Shah, Pant 2005; Shrestha 2005; Shrestha, Shrestha 2006; 
Shrestha 2001; Tiwari n.d.). Adhikari (1998) argues that the loss of public space has led to a dramatically low provision of communal meeting areas in the new neighbourhoods. Consequently, two distinct forms of neighbourhood public space currently exist in the valley (Sharma 2006). The traditional public spaces reveal a constructive design inherent in their outstanding ability to accommodate a significant level of social life and activity (Tiwari 1989). Most notably, public space still remains the heart of the urban neighbourhoods in the traditional towns, and is widely in use at this date (Chitrakar 2006; Shokoohy 1994). However, due to the lack of proper urban development control, the past practices of the development and utilisation of neighbourhood public space has now been significantly transformed in the new neighbourhoods (Chitrakar et al. 2014, 2016). This paper aims to explore this transformation of public space in examining how the two key dimensions of public space - the provision and the use - have changed in the new neighbourhoods of the Kathmandu Valley.

Most definitions of public space suggest that it is essentially a physical setting to perform a range of social activities taking place within a community (see Carr et al. 1992; Madanipour 1996; Tibbalds 2001). It is generally characterised as a space owned and controlled by a public agency. There is, however, an increasing trend to use semi-public space for public purpose in contemporary cities (Oldenburg 1989; Worpole, Knox 2007). On the other hand, public life has also been traditionally taking place in the streets and community buildings, in addition to the open space. Therefore, this paper adopts a boarder definition of public space to mean any "social space", both outdoor and indoor ${ }^{1}$, with a potential to develop social contacts (regardless of ownership and typology).

\section{Urban change and the changing nature of contemporary public space}

Cities have been in a continual state of transition since their evolution. However, a marked change in the urban form and life has occurred over the past centuries, following the large - scale industrialisation and modernisation in the western world. The industrial revolution led to the unprecedented rise in urban population and the subsequent growth and transformation of urban regions around the globe. Carmona et al. (2010) argue that the evolution of physical and electronic means of communication between locations and rapid mobility made possible by new develop-

\footnotetext{
1 The indoor locations of privately owned public spaces have not been considered in this study.
}

ments in technology have altered the traditional and centralised mode of urban form. It was a period of a major transition from a traditional to modern era, in which the older scale and pace of urban development was undertaken by rapid and intense growth of industrial cities. While the compactness of the traditional city disappeared in modern urban environments, the fragmentation of geographical areas characterised the emerging city form, resulting in urban sprawl and polycentric cities (Carmona et al. 2010).

There are social consequences related to the dispersion of cities (Madanipour 1999). Wirth (1938) argues that the fragmentation of urban life in modern society has led to the decline of close community networks. According to Madanipour (2003), society has now become increasingly individualised as social fragmentation has found clear manifestations in the growth of suburbia and in the segregation of social groups. The fragmentation of urban environments has resulted in a loss of well-defined territories, in which the "historic social bonds between individuals have become weakened" (Madanipour 2010: 1).

The nature of public space is closely related to the nature of cities (Madanipour 2010). While the modern cities have undergone rapid transformation, the contemporary public space is also changing. Empirical studies report that, due to urban change, modern cities and residential developments are confronted with the problems of the loss of public space and the decline of public realm (see Banerjee 2001; Carmona et al. 2010; Ellin 1996; Gehl 1987; Jacobs 1961; Madanipour 2010; Oldenburg 1989; Orum, Neal 2009; Sennett 1986; Tibbalds 2001; Trancik 1986). Madanipour (1999) argues that public space is treated as a residual space in the modern urban environment, and gets least priority in the development process. Others relate it to physical and technological changes in the rise of "the automobile, the suburbs and the internet" (Orum, Neal 2009: 201) and observe in "the reduced availability of, and significance attached to public space" (Carmona et al. 2010: 141). For Madanipour (2010:4) "the loss of public space has symbolised the loss of idea of the city".

Contrary to the conventional assumptions, Worpole and Knox (2007: 4), however, claim that "public space in neighbourhoods, towns and cities is not in decline, but is instead expanding". They call for a need to reframe the debate of the loss of public space in broader terms and to consider how people use different urban places regardless of their ownership and appearance. If considered this way, they claim that almost any place offers potential as a public space. The growing use of "third places" in contemporary cities in the forms of cafes, restaurants and other similar locations 
as suggested by Oldenburg (1989) may be seen from a similar perspective. Indeed, the recent decades have seen a notable shift in public sphere, from those observed in public locations to the semi-public or private realms, largely flourishing in the privately owned public spaces. Scholars point out at this phenomenon as the privatisation of public space in contemporary cities (see Banerjee 2001; Madanipour 1996; Trancik 1986). Carr et al. (1992: 361), however, make a cautious note on increasing private control of the public realm, as they argue that "it tends to put [public] space in the hands of those who view the physical environment as a means for creating profits".

\section{Public space in traditional neighbourhoods of the Kathmandu Valley}

Traditional settlements of the Kathmandu Valley boast a fine provision of public space that are distributed over the entire town to offer a physical setting for social life. These towns as they appear today were mostly built during the Malla ${ }^{2}$ period from the $13^{\text {th }}$ to the $18^{\text {th }}$ century by the Newars ${ }^{3}$. The traditional towns have a definitive urban character of compact and dense settlements, with urban spaces organised in a very unique and innovative way. Tiwari (1989: 95) suggests that these towns exhibit "a distinct set of [urban] squares with a clear hierarchy of social [and] cultural activity" that include the Durbar (palace) square, the market square, the residential neighbourhood square and the private residential square. In every principal Malla town, there is only one Durbar square, whereas other square types are numerous and widespread, and are an essential feature of urban neighbourhoods (see Fig. 1). Each neighbourhood is centred around more or less spacious public squares (Gutschow, Kolver 1975), and follow two basic approaches of spatial configuration: a) space formed at street intersection - the street square; and b) the enclosed space of a courtyard.

With several streets culminating in it, the market square represents a neighbourhood public space formed at the street intersections. Most street squares reflect a nodal point of a town (Chitrakar 2006; Tiwari 1989), where no symmetry is found in the physical layout, but make highly informal urban space settings. Whereas the shape and size of the street squares greatly vary, each space exhibits a unique design in

\footnotetext{
2 The Malla kings developed the Kathmandu Valley as towns a major trade and administrative centre and also contributed to its rich social fabric and highly developed cultural patterns.

3 The Newars are indigenous people of the Kathmandu Valley, who are solely responsible for its outstanding development in the medieval period.
}

terms of spatial configuration and enclosure, and the use and placement of the elements of urban interest. The residential neighbourhood and private residential squares form neighbourhood open spaces organised around a courtyard. A combination of these squares often forms a series of interconnected courtyards embedded within an urban block (see Fig. 2).

The amount of public open spaces present in the traditional neighbourhoods averages about $12 \%$ of the total housing area (Adhikari 1998). These open spaces consist of many elements of urban interest that serve both functional and visual purposes. Chitrakar (2006) identifies a number of these elements that include temples and shrines, pati (public rest house), wells, dhara (stone water spouts), stupa and chaitya (Buddhist shrines) and dabali (an elevated platform for a range of socio-cultural uses). In addition to these, many traditional neighbourhood spaces also consist of a range of community buildings in or adjacent to the open space. These buildings form a constituent element of a neighbourhood (Pant, Funo 2007), and contribute to the making of the public realm.

Traditionally, the Newars lived in an extended family, and demonstrated considerable ease among neighbours as they believed in communal life philosophy

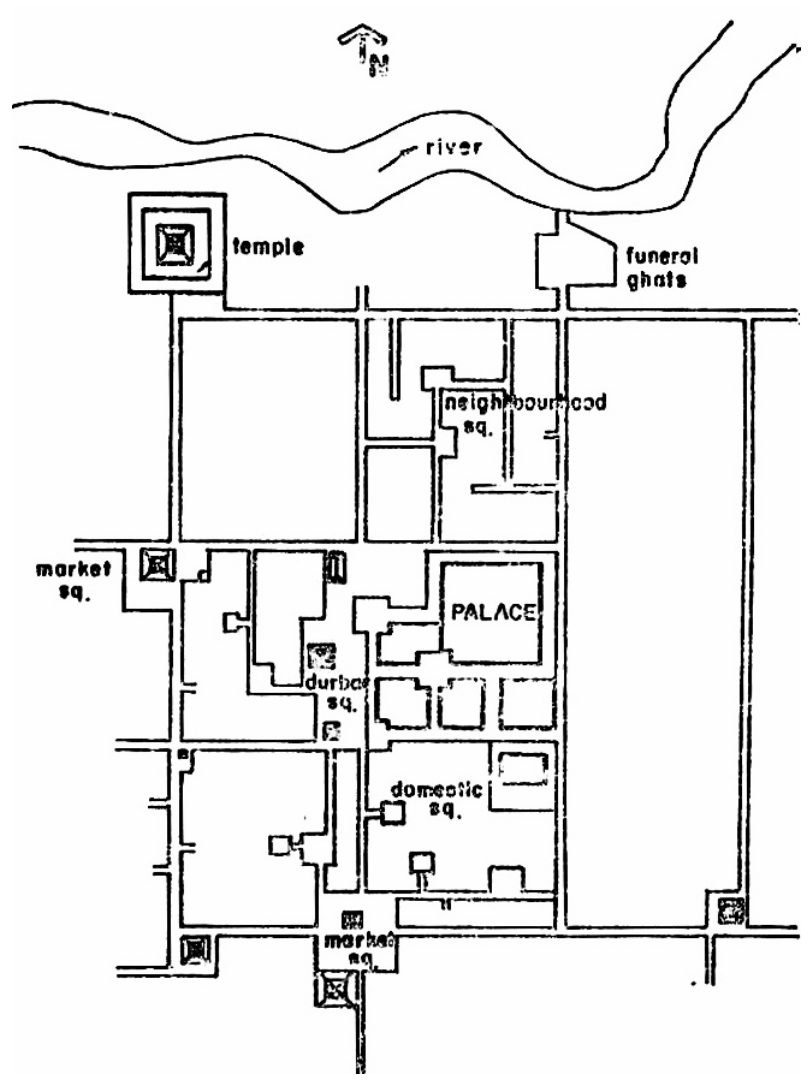

Fig. 1. A diagrammatic layout of a typical Malla town showing a hierarchy of urban spaces

Source: Tiwari 1989. 


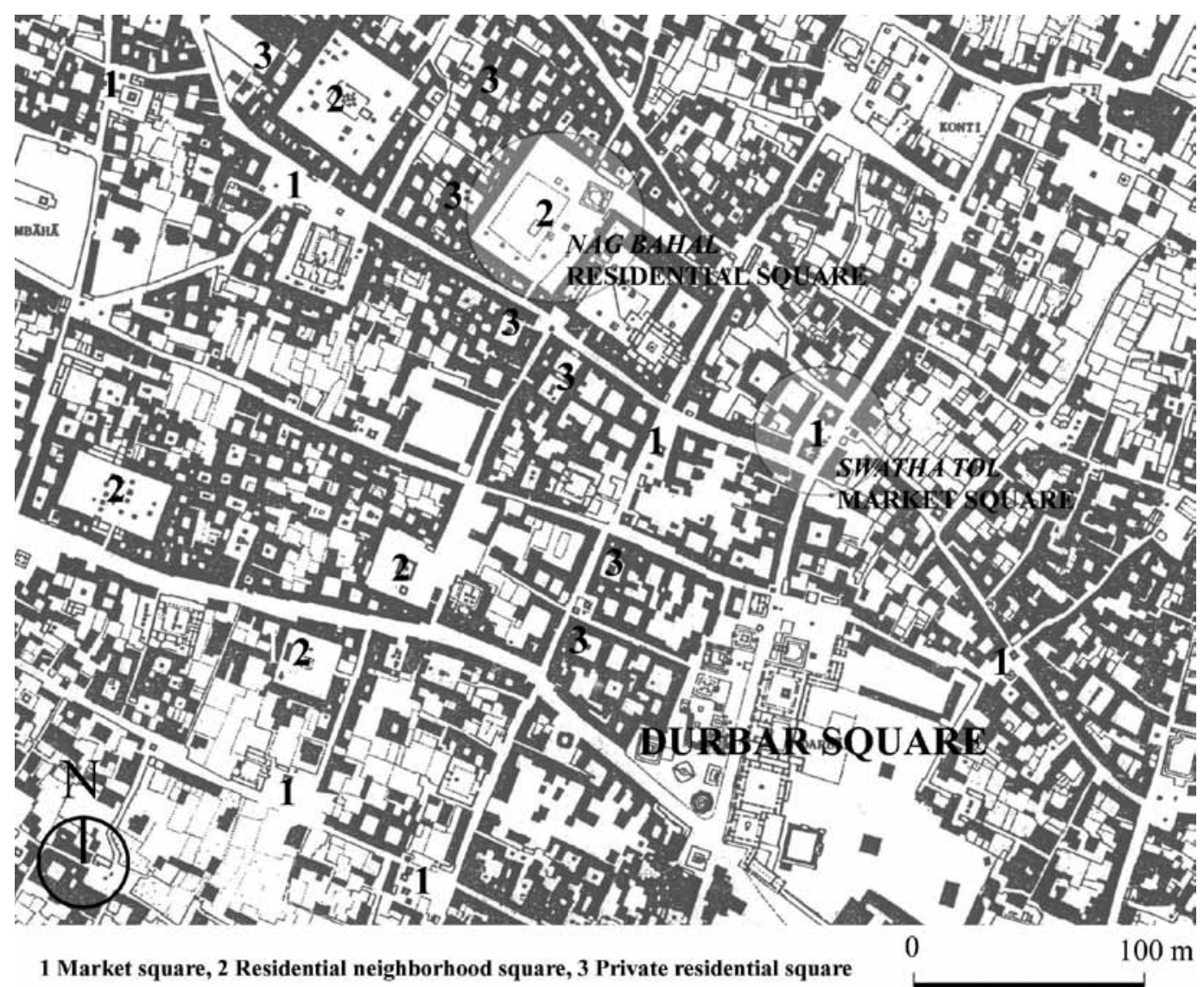

Fig. 2. An urban pattern of a traditional town showing the hierarchy and distribution of urban squares Source: Chitrakar 2006.

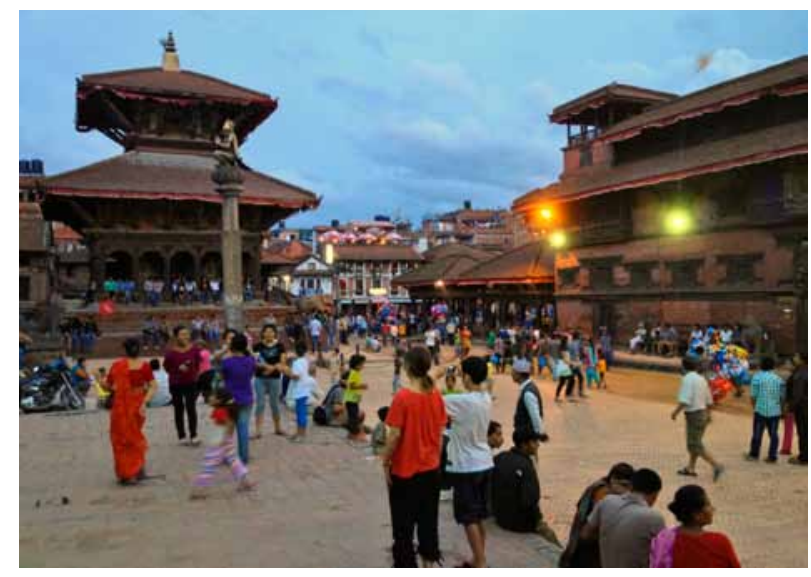

Fig. 3. An image showing the use of traditional public space in the Kathmandu Valley Source: Authors.

(Tiwari 1989). Social networking and exchange have always been a significant part of their life, which has led to the extensive use of public space in everyday life as well as during festivals and social occasions (see Fig. 3). Children play and grow up together in neighbourhood squares (Shokoohy 1994); adults or elderly people can be found having a chat with their fellow neighbours, sitting on a plinth of a nearby pati. In addition, streets and other public buildings are also equally the venues of everyday life (Hosken 1974). During feasts and festivals, the streets and squares acquire a new ambience with intense activities related to the socio-cultural and religious use of public space.

\section{Research methods}

This research was carried out in three recent neighbourhoods of the Kathmandu Valley. Because the valley is currently comprised of a diverse urban form, the selection of the study areas was based on the emerging urban typologies in the background of different urban development systems. The selected study areas consisted of both planned and unplanned new neighbourhoods that include: a) Budhhanagar Tole ${ }^{4}$ (BT); b) Gongabu Residential Area (GRA); and c) Civil Homes, Phase III (CH - III). The context and location of each study neighbourhood within the Kathmandu Valley is given in the Figure 4. The BT represents an unplanned development of the new neighbourhoods

4 Tole means an urban neighbourhood in the local language. 


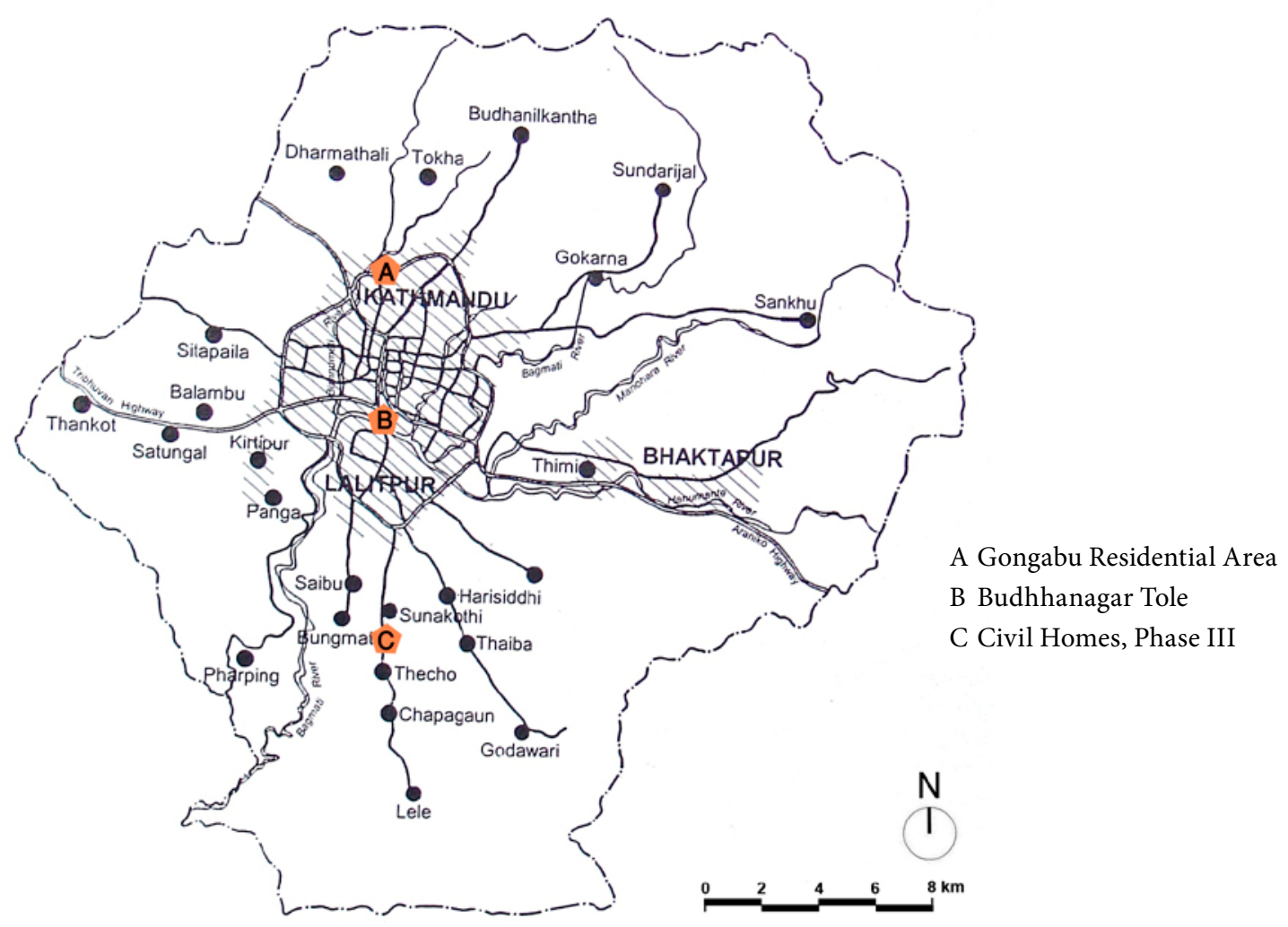

Fig. 4. Map of the Kathmandu Valley showing the study areas Source: Modified from KMC/World Bank 2001.

in the valley. Such a spontaneous growth of the new neighbourhoods is largely prevalent, and covers most of the newly developing/developed areas in the valley. The GRA is a planned new neighbourhood initiated by the government using the Land Pooling approach, which aimed at controlling haphazard urban growth. The CH - III represents the development of a gated community by a private housing company. In each study area, the research adopted the multiple methods of data collection that included site observations and interviews with residents.

\section{Site observations}

A total of 20 public spaces were observed in the three neighbourhoods - seven from the BT, eight from the GRA, and five from the $\mathrm{CH}$ - III. The observations also included three major street junctions in the GRA and four in the BT. Site observations were carried out in two categories. First, the observations of public spaces were conducted to record the physical setting and characteristics of public (open) spaces, also taking observation notes. The site features recorded include space type, location and accessibility, shape and size and the use of the elements of urban interest, including the landscape features. Secondly, semi-structured observations of public spaces were carried out to examine their use, focusing on the location and timing as well as the user groups and activity types. The observations were structured based on time categories that included morning (6-7 am), afternoon (2-3 pm) and evening $(6-7 \mathrm{pm})$ on a weekday and a weekend (Saturday). The strategy during the observations was to remain participant in the activities taking place in public space, depending on their nature and the desired level of interaction with the users.

\section{Interviews}

The study conducted open-ended and in-depth interviews with 35 residents across the study areas. Some participants of the interviews were key informants with rich information on the development history of a neighbourhood. Most of these informants have assumed an active role in the local community-based organisations within the neighbourhoods. Personal approach was used to contact and interview these informants, whereas snowball sampling helped identify other participants. The interview questions focused on the provision and use of public space within the neighbourhoods. 
Table 1. Open space requirements for planned residential development in the Kathmandu Valley

\begin{tabular}{cc}
\hline Development area & Open space requirement (excluding roads) \\
\hline 5 to 10 Ropani $^{5}$ (0.25 to $\left.0.50 \mathrm{ha}\right)$ & $5 \%$ of total land area \\
\hline More than 10 to 25 Ropani $(0.50$ to $1.27 \mathrm{ha})$ & $4 \%$ of total land area \\
\hline More than 25 to 100 Ropani $(1.27$ to $5.09 \mathrm{ha})$ & $3.5 \%$ of total land area \\
\hline More than 100 Ropani $(5.09 \mathrm{ha})$ & $2.5 \%$ of total land area \\
\hline
\end{tabular}

Source: Building By-laws (KVTDC 2007).

\section{Public space in new neighbourhoods of the Kathmandu Valley}

Planning context for the provision of public space

Although the authorities have taken approaches to regulate urban growth in the Kathmandu Valley since the 1960s, the existing regulations are still weak and lack a comprehensive mechanism. The Kathmandu Valley Town Development Committee (KVTDC) (now Kathmandu Valley Development authority) has not been able to prepare urban planning and design guidelines for the valley's newly developing areas (Shrestha 2010). While the Building By-laws (KVTDC 2007) have some guidelines for planned residential development (taking place through Land Pooling scheme and private housing development), mainly focusing on the access roads, open space requirements and the geometry of residential plots, there is a lack of effective tools to regulate unplanned development of the new neighbourhoods. The consequences are directly seen in the lack of a mechanism to develop adequate and responsive public spaces in the new neighbourhoods. Table 1 gives an outline of open space requirements in the planned new neighbourhoods based on the size of residential development.

\section{Provision and use of public space in Budhhanagar Tole}

The BT is a new and large neighbourhood ${ }^{6}$ with more than 1200 households located in the southern periphery of Kathmandu Metropolitan City (KMC). The residential development in the $\mathrm{BT}$ has been spontaneous, due to the lack of planned intervention by regulatory bodies, with the private land brokers playing a major role in the physical development. This has resulted in the growth of a neighbourhood with the urban blocks, including the street networks and the residential plots, developed in a haphazard manner

\footnotetext{
5 This is a traditional system of measuring the land area in the Kathmandu Valley. One Ropani is equivalent to $509.39 \mathrm{~m}^{2}$.

6 The interviews with the residents took place only in the two smaller communities i.e. Budhhanagar Ekta Tole Bikash Samiti (BETBS) and Sri Shanti Marg Tole Bikash Samiti (SSMTBS) with a total of 150 households. However, the observations were conducted in the entire neighbourhood.
}

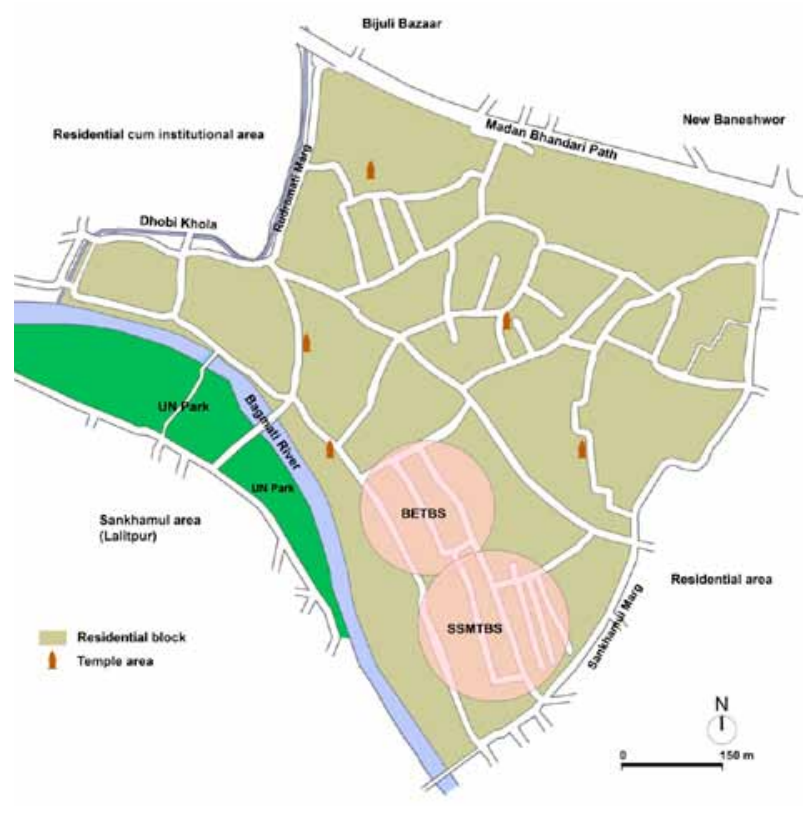

Fig. 5. Map of the Buddhanagar Tole Source: Modified from KVTDC 2007.

(see Fig. 5). In a similar manner, the development of the BT has not been conducive in providing sufficient land for public purpose. While the streets appear to be the only public space in this neighbourhood, practically no open space exists in the BT. A few tiny open spaces may be seen within the neighbourhood but such spaces are mostly unattended, although some others locate a number of smaller temples (see Fig. 6). The total amount of these open spaces is less than a Ropani, and it is definitely far too less for the size of the residential development. At the same time, the BT also lacks other community facilities, in particular, the buildings for community purpose.

The loss of public space in the BT has largely influenced its use both on a daily basis as well as during social events. The existing public spaces such as the temple areas generate a very small amount of daily activities as the residents do not visit them on a regular basis. Such activities are observed only in a few parts of the neighbourhood that include streets and associated spaces such as footpaths or shop fronts. Although most BT streets are narrow (less than $4 \mathrm{~m}$ ) and without footpaths, and often cause conflicting situations among 


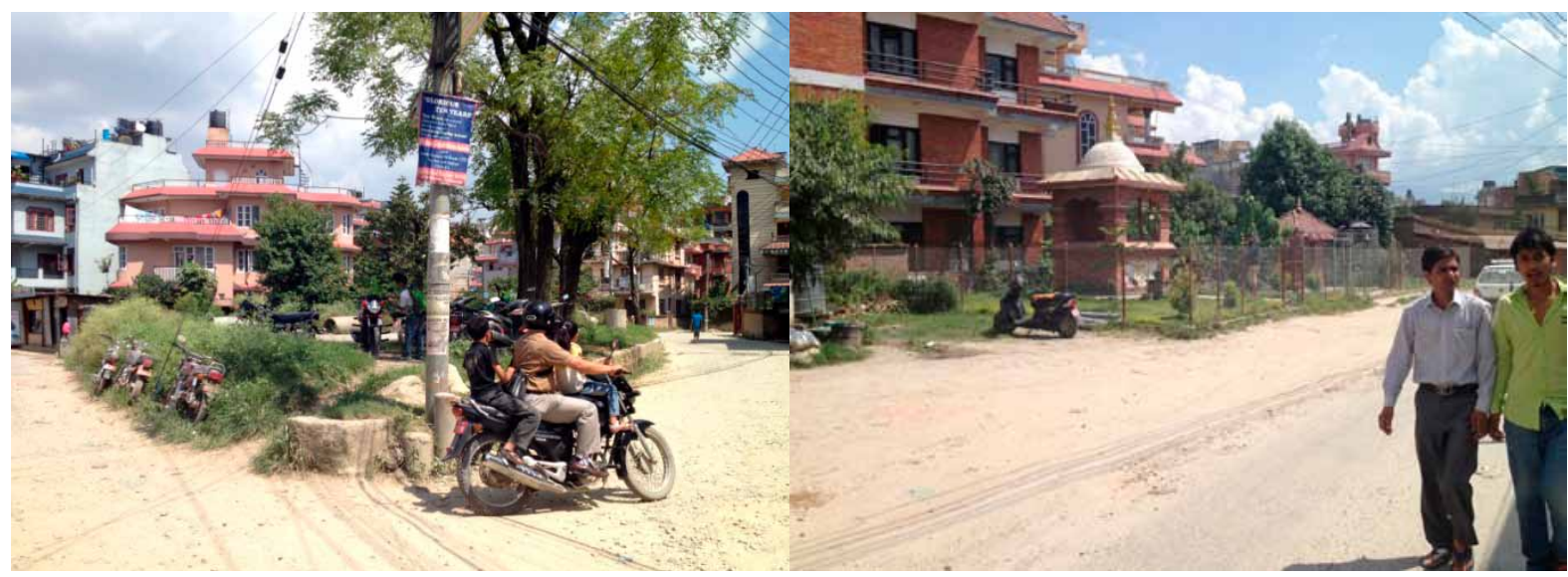

Fig. 6. Some existing public open spaces in the Budhhanagar Tole Source: Authors.

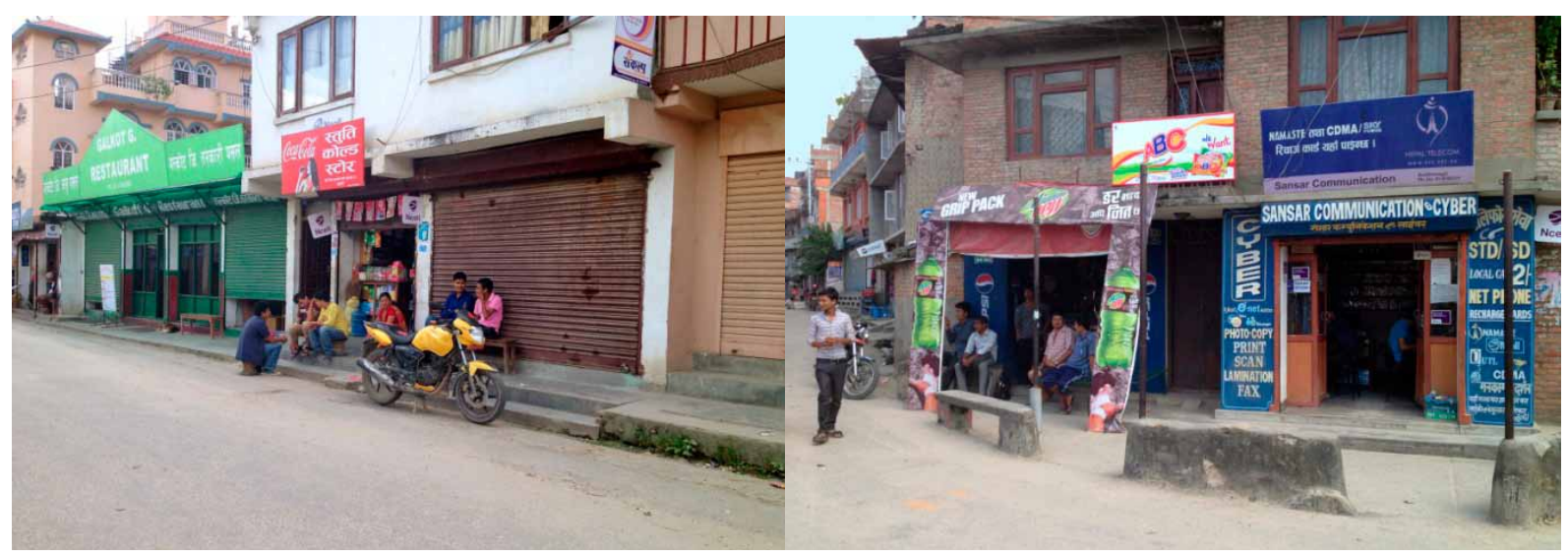

Fig. 7. The local residents using the shop fronts in the Budhhanagar Tole Source: Authors.

the users, pedestrians generate a significant amount of activity focused around both walking for commuting and for health and recreational purposes. A large portion resident goes for a walk around the neighbourhood streets mostly in the morning. Such walking also works as a catalyst to generate other public activities such as meeting and greeting a mong neighbours. Other street activities include children and teenagers playing in inner streets.

Daily activities that are focused around the pedestrians also take place on footpaths and shop fronts along the major streets. The local cafés and restaurants located in these streets usually have a provision of an outdoor space to accommodate the customers and/or the local residents. The residents quite often engage in a conversation while having a drink in such semi public spaces. People can also be seen gathered at the front space of the local stores or newspaper stands. Such spaces usually have a couple of chairs or benches to sit. People even like to sit on a plinth of the building if there is no provision for sitting (see Fig. 7).
Formal social events are not frequently held in the BT, mainly due to the relatively inactive nature of the local community in social networking. The interviews revealed that not many residents participate in such events. The limited number of social events, however, takes place either on the streets or in privately owned public spaces. According to an executive member of a local organisation, the programs organised to exchange greetings during the Dashain ${ }^{7}$ festival are either held at the premises of a local school or at a party palace ${ }^{8}$. The neighbourhood committees organise meetings several times a year, which are also held in the local school. The Teej ${ }^{9}$ festival was celebrated last year in a local restaurant. While the neighbourhood locates two party palaces and numerous

\footnotetext{
7 It is a 15-day-long national festival in Nepal celebrated by the Hindu people.

8 These are the multipurpose private venues for social events and public gathering, used mostly for large scale feasts.

9 It is a festival primarily celebrated by Hindu girls and women, with songs, dancing and praying rituals.
} 
restaurants, there is an increasing tendency of using such spaces for neighbourhood social events.

\section{Provision and use of public space in Gongabu Residential Area}

Located in the northern peripheral area of the KMC, the GRA is the first planned residential neighbourhood developed by the government in 1996. The total site area of the GRA is 14.2 ha, with a total of 406 residential plots. Among these plots, a total of 14 plots of different shapes and sizes represent the public open spaces (see Fig. 8). This comes out to be $4.9 \%$ of the total development area, which is almost twice the actual requirement according to the existing standards. However, the master layout plan shows that the layout of open spaces follows no logic of spatial organisation; it is rather random and ill-conceived, which is evident from a series of five pockets of open spaces laid out along the high voltage transmission line running across the neighbourhood. With no doubt, the construction of built structures is not practical in such open spaces.

Furthermore, most of these open spaces are situated in inner urban blocks that place them away from daily pedestrian movement. The open spaces are also poor in terms of landscape design as they lack elements of interest and show no or less sign of physical design or development. The only exception is the temple area. With a number of temples, smaller shrines and other small and large religious structure of interest to both Hindus and Buddhists, the temple area is the most happening public open space in the whole neighbourhood (see Fig. 9).

Site observations reveal that not all the open space plots are truly open to the public. At least three of these plots already consist of built structures to make them inaccessible. But worse than this, a number of other plots have been either temporarily closed or leased out

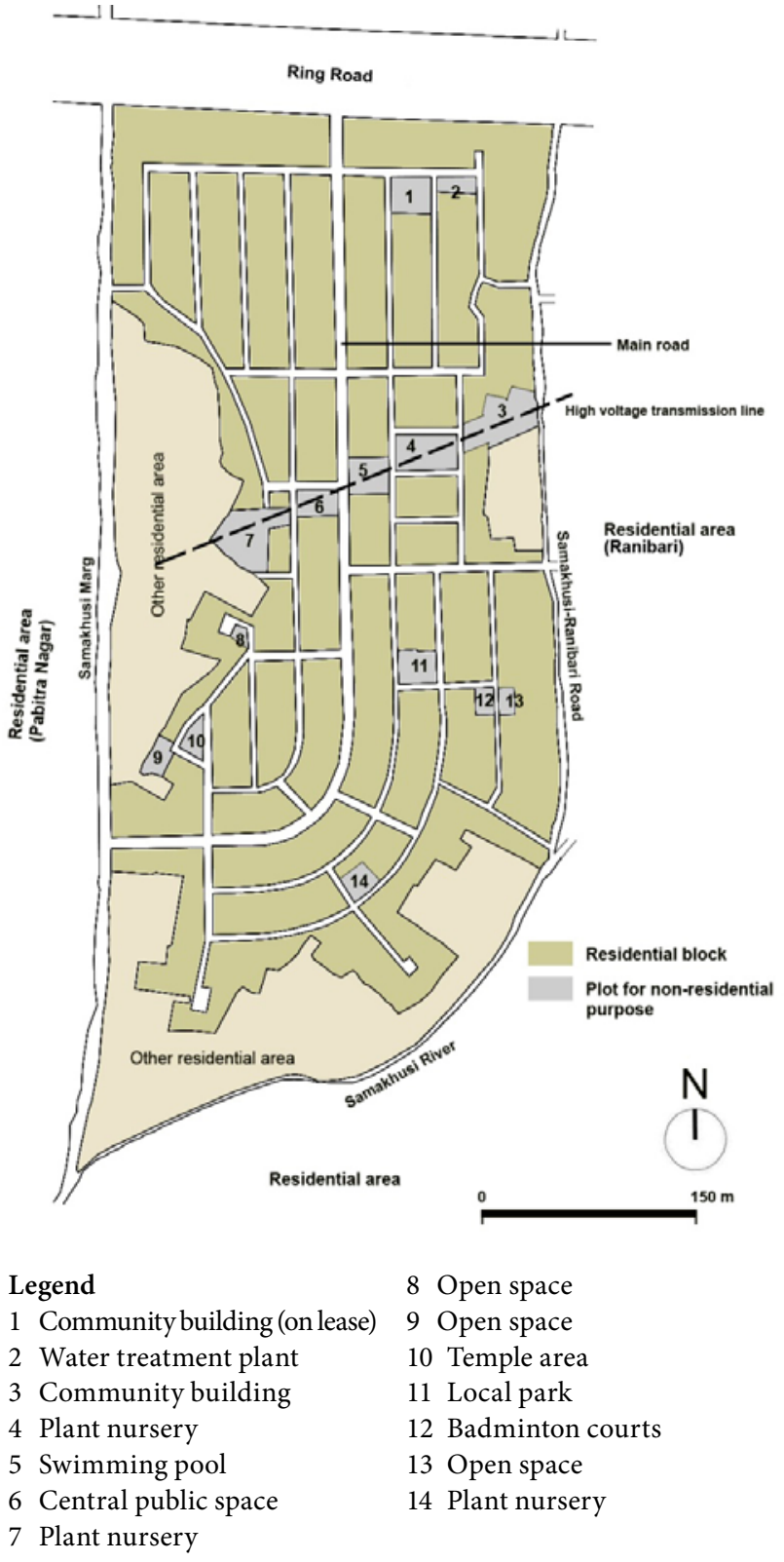

Fig. 8. An allocation of open spaces in the GRA Source: Modified from KVTDC 2007.

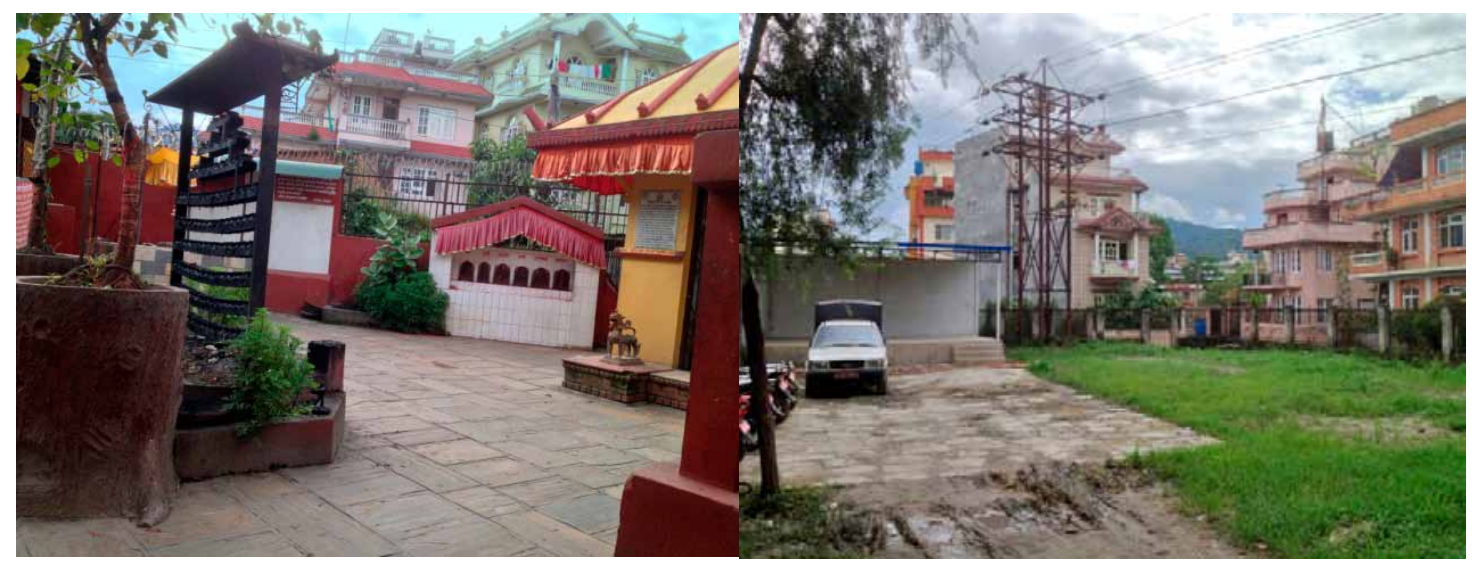

Fig. 9. The temple area (left) and the central public space in the GRA Source: Authors. 
to the private parties. The only two open spaces that open daily for the residents are the temple area and the open spaces with badminton courts. Although the central public space is one of the major open spaces of the GRA, it has been leased out for use by a private college located nearby.

There are two community buildings in the GRA. One of them is a two-storey building that locates an office of a local community-based organisation, along with other community spaces. The other community building is on a lease and cannot be used by the local community.

The existing drawbacks with the public spaces in terms of both the design and management (including poor maintenance, the lack of proper access and commercial use) seem to have affected their use, both on a daily basis as well as during social events. Observations show that not many people use public space every day as daily activities in the GRA are concentrated on a few locations only such as the temple area, the open space with the badminton courts and the community building with the local organisation's office. The temple area opens for limited hours in the morning and evening to generate some amount of daily activity with the local people visiting mainly for worshiping and performing religious songs. Some local youth gather each morning in the open space with the badminton courts for playing. The residents use it at other times, mostly in the evening, for leisure. Similarly, some people visit one of the community buildings for leisure and recreational purposes as they come around to read newspapers and to meet and chat with the neighbours, whereas some local children come to play Table Tennis.

However, streets are relatively more accessible to the residents than open spaces and therefore, comprise a large portion of daily activity. The GRA comprises of three types of streets based on their width $-8 \mathrm{~m}$ wide main road, $6 \mathrm{~m}$ wide connector roads and $4 \mathrm{~m}$ wide inner roads. Ground floors of most buildings on the main road are used for commercial purposes with either shops or restaurants. There is a provision of about $1.2 \mathrm{~m}$ wide footpaths on both sides of this road. Other streets have no footpaths. Despite the intruding vehicles, the GRA streets generate a significant level of daily activity with walking that occurs for two purposes - commuting and health and recreational purposes (mostly morning walks). Besides walking, the local children and teenagers play in groups in many parts of the streets, mostly during the evening hours. As part of the street space, footpaths and shop fronts located along the main road also comprise daily activities focused around the pedestrian. Outdoor spaces of the local cafés and restaurants accommodate local residents with a couple of chairs or benches to sit on. People, both young and elderly, engage in a conversation while having a cup of tea (see Fig. 10). The grocery outlets and food stores may not serve drinks or snacks, but the residents still consider them as places to keep in touch with neighbours. Such activities take place throughout the day, but are more intense in the morning or evening.

In the GRA, social events and the celebration of festivals have largely contributed to the use of public space as compared to the daily activities. During such events, the ambience of the neighbourhood fully transforms with a considerable amount of life and activity taking place in public spaces. The open spaces that are kept closed or inaccessible at other times are opened to the public during these occasions. Some such venues are the central public space, the temple area and its adjacent open space and the community buildings. The central public space is a venue for the events such as the formal

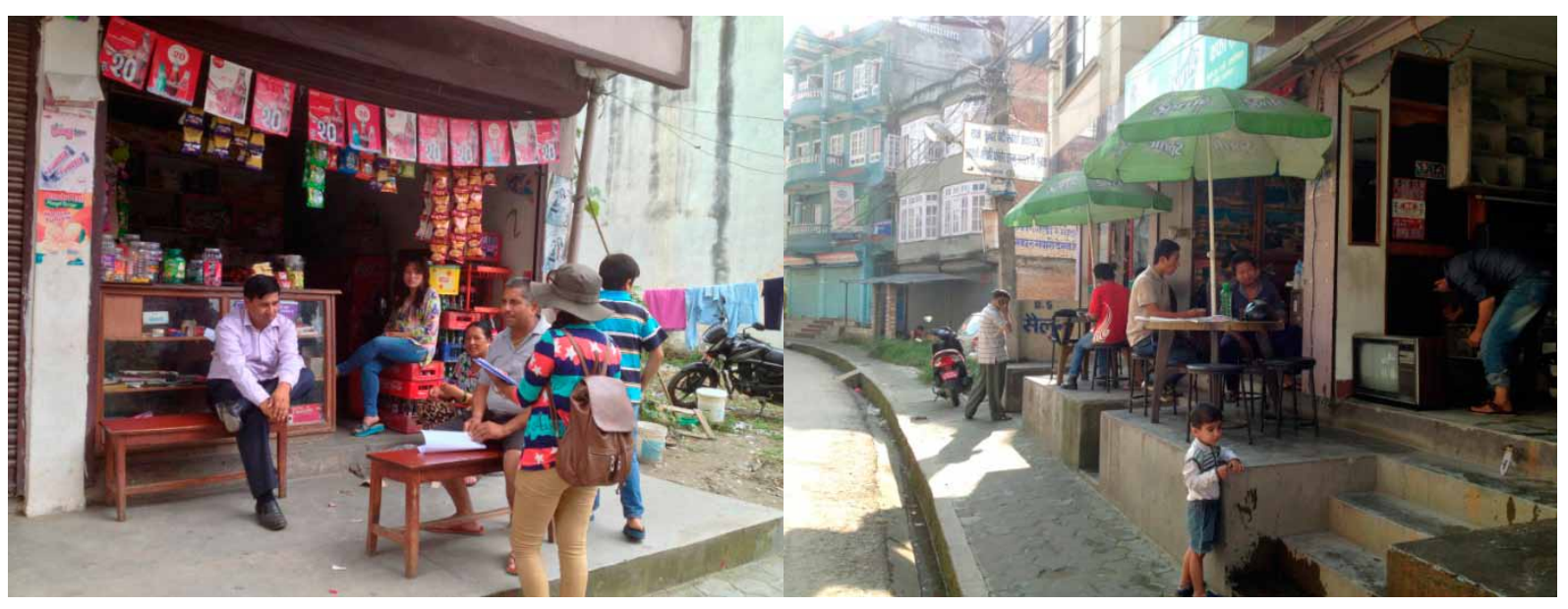

Fig. 10. The local residents using the shop fronts and the local cafes along the main road in the GRA Source: Authors. 
gathering of the local organisations, including meetings and seminars, community feasts and a mass meeting by political parties. The local people gather in the temple area to celebrate festivals such as Teej and Dashain. The open space near the temple area is used for both formal and informal events of the local organisations, including community feasts and the programs to celebrate Dashain and a New Year. The community buildings are the venues for events such as meetings, health check up camps and blood donation programs. Moreover, some events by their very nature are celebrated on the streets such as the annual event of the Ganesh Puja, which consists of the procession of the chariot of Lord Ganesh around the neighbourhood streets.

\section{Provision and use of public space in Civil Homes, Phase III}

The $\mathrm{CH}$ - III is a gated community developed by the Civil Homes Private Limited as a commercial residential development. Located in Thecho in Lalitpur district, the area of the development is 6.4 ha and it has 196 housing units. Its site planning shows a clear geometry of a grid iron pattern used to organise housing units within the building blocks. Yet the edges are irregular that give the entire area no definite shape.

The $\mathrm{CH}$ - III developers have allocated a total of eight plots as public open space ${ }^{10}$ in its development, and this comes out to be $4.4 \%$ of the total developed area (see Figs 11 and 12). The provision is thus almost double the actual requirement. Among these spaces, the two parks (the East Park and the West Park) occupy the central location, with a symmetrical arrangement along the main entry road. However, site observations indicate that there is a lack of proper distribution of open spaces. The other public spaces such as the children's playing area, the covered public space and other open spaces occupy peripheral locations so that they may not be easily accessible to the residents. Some open spaces in such locations (along eastern boundary) are also not usable because of the lack of a levelled surface. Furthermore, the open spaces in the $\mathrm{CH}$ - III lack a proper development, resulting into no or very little elements of interest in most of them. In addition to the open spaces, the $\mathrm{CH}$ - III also houses a community centre, which consists of a range of community facilities for use by the residents.

The physical environment of the $\mathrm{CH}$ - III appears to be conducive for public activity as compared to the

\footnotetext{
${ }^{10}$ Some other plots designated for use as a school, utility and parking area and a swimming pool are not included in this list although they count towards the total sum of open space provision for the by-laws purpose.
}

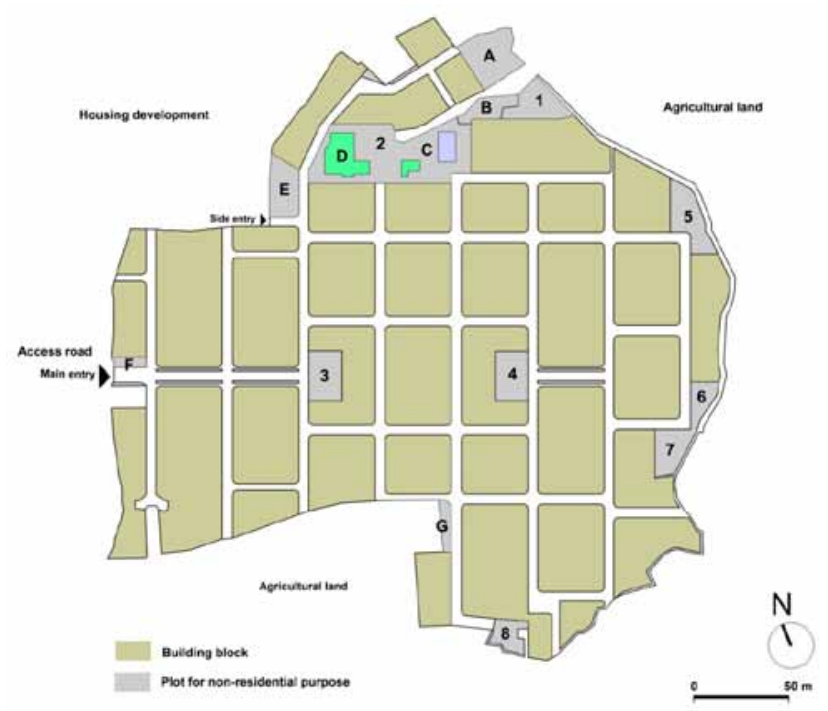

Legend

1 Open space

2 Children's playing area

3 West Park

4 East Park

5 Open space

6 Open space

7 Open space
A Plot for school
B Utility area
C Swimming pool
D Community centre
E Parking area
F Guard house
G Overhead water tank

8 Covered public space

Fig. 11. Open spaces and other community facilities in the $\mathrm{CH}$ - III

Source: Modified from www.civilhomes.com.

other neighbourhoods considered in this study, although the residents have complaints about the lack of regular maintenance of public spaces. Yet, the residents feel safe and comfortable within the housing environment, due to the tight security measures and a low volume of traffic on the streets. This is reflected in the daily use of public space by most of its residents. Similar to the previous neighbourhoods, most residents indicated that they use the streets as a public space. Designated open spaces such as the local parks and other spaces are not in use as much as the residents use the streets. The parks are used only by a small portion of the residents in the morning or evening for leisure and recreation purposes. At times, some local children come to play in the park with a parent; the elderly people may be found mostly sitting there in the evening. Most visitors come to the parks while they roam around the neighbourhood, whereas only a few of them visit with a specific purpose.

Another open space used daily in the $\mathrm{CH}$ - III is the children's playing area, where the local children play in small groups, mostly during the afternoon hours on the weekdays or throughout the day during the weekends. The playing equipments such as the swings and slides do not seem to be much in use. Although there is a low 


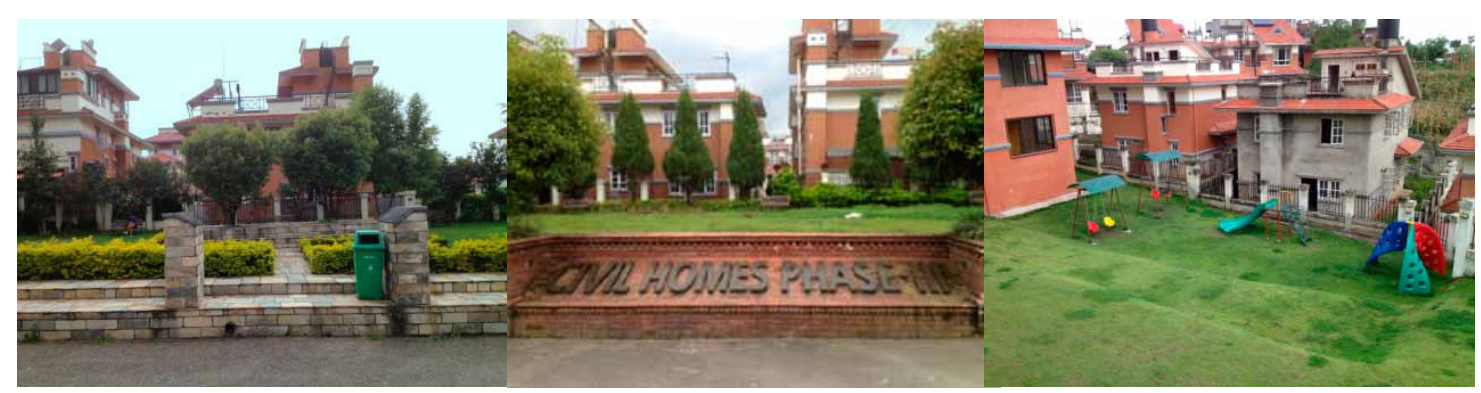

Fig. 12. East Park (left), West Park (middle) and the children's playing area in the $\mathrm{CH}$ - III Source: Authors.

turnout of residents using its facilities, the community centre is also used on a daily basis for several purposes such as health and fitness, eating in a restaurant and buying household items from the convenience store.

The $\mathrm{CH}$ - III streets that contain the most amounts of daily activities are $4 \mathrm{~m}$ in width and have no footpaths, except for an $8 \mathrm{~m}$ wide short segment immediately after entering the housing area and another segment of the same width three blocks beyond this. The footpaths are $1.5 \mathrm{~m}$ wide. The streets are primarily used for walking and their commercial use cannot be seen (see Fig. 13). However, walking does not form a part of commuting as most resident use private vehicles to commute outside the neighbourhood. It instead represents a larger part of leisure and recreational activities, and is common in this housing community. Most residents go for a walk in the morning and evening, generating a moderate level of outdoor activity on the streets. In addition, the streets are also frequently used for playing by the local children.

Although social events based on tradition and culture as well as contemporary needs and practices are usually organised on a monthly basis in the $\mathrm{CH}$ - III as the local community-based organisation is relatively active socially, the residents' participation is less satis- factory. The community centre is the venue for most of the social events - a program to celebrate the Teej festival was recently held in the community hall. Since the physical environment of the parks is not conducive and does not offer protection against weather conditions, it is the less preferred choice for social events at present. The covered space, on the other hand, although it has a roof covering, is less used since it is not only inconveniently located but also lacks supporting facilities. As far as the streets are concerned, these do not form a venue for social events in the $\mathrm{CH}$ - III.

\section{Discussion and conclusions}

Findings from this study reveal several changes in the provision and use of contemporary neighbourhood public space in the Kathmandu Valley. Overall, there is a loss of public space, particularly in the unplanned new neighbourhoods. As far as the provision of public space in the planned new neighbourhoods is concerned, it is not satisfactory in terms of both the quality and quantity, although it meets the requirements of the current by-laws (KVTDC 2007). The GRA and $\mathrm{CH}$ - III cases reflect this situation, in which the planning and design of public open space exhibit a number of drawbacks in terms of location, accessibility, design

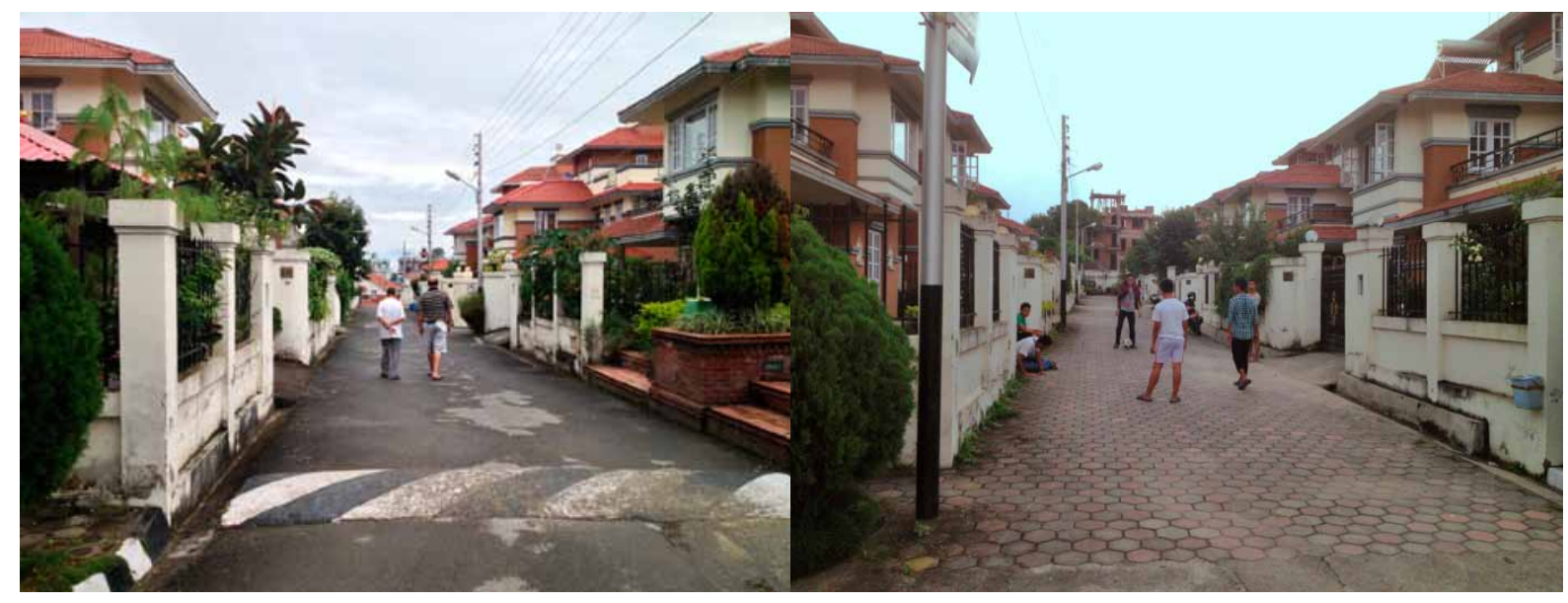

Fig. 13. The residents walking (left) and children playing in the streets of the $\mathrm{CH}-\mathrm{III}$ Source: Authors. 
and landscape features. Comparatively, most new neighbourhoods have less amount of public open space than an average traditional neighbourhood (Adhikari 1998). At the same time, the existing open spaces do not contain basic amenities or elements of interest for both active and passive engagement of the users. The open spaces are thus less inviting, and also, inappropriate for use during adverse weather conditions. On the other hand, the community buildings that form a key element of the valley's traditional neighbourhoods (Pant, Funo 2007) have also been lost in the new neighbourhoods. The case of the BT clearly exemplifies this, which is very much likely to be the case with other unplanned new neighbourhoods as well. In the planned new neighbourhoods, the provision of such buildings is less satisfactory, due to the drawbacks such as inconvenient location, inadequate space and the lack of proper access. These findings suggest that public spaces are no longer the central elements of the new neighbourhoods, but have received least priority in the development of residential neighbourhoods (Madanipour 1999).

The transformation of public space is also evident in the changing spatial configuration of public (open) spaces. In the new neighbourhoods, the open spaces have been developed in the form of "individual plots", without taking into consideration their immediate contexts, which is in a strong contrast with courtyard and other nodal spaces of the traditional neighbourhoods (Chitrakar 2006). The physical form of the study neighbourhoods shows that the open spaces and buildings do not complement each other, and little or no relationship exists between the open spaces and streets, which is an essential character of the traditional urban space (Tiwari 1989).

The findings suggest that the neighbourhood streets are emerging as a dominant social space, due to the loss of open space and limited access to the existing spaces. However, the development of these streets does not appear to be conducive to accommodate pedestrian use and activity because of the narrow width, without a provision of footpaths in the most parts. While there is less a concern for pedestrians in the design of the neighbourhood streets, the intrusion of vehicles brings a significant amount of conflict among the space users. These factors indicate a lack of social quality of neighbourhood streets as compared to the streets in the traditional areas.

Another key change in the provision of neighbourhood public space is noticed in the gradual rise of privately owned public spaces for social contacts. The findings indicate that new types of social spaces, such as the cafés, restaurants and other similar venues, are emerging in the new neighbourhoods. The growth of these venues supports what Oldenburg (1989) refers to as the "third places", and suggests that the social spaces for public gathering are expanding (Worpole, Knox 2007). This may be seen as a notable shift in the provision of contemporary public space in the Kathmandu Valley. At the same time, it also indicates that the residents do seek for an "alternative" to the loss of public open spaces or to the unfavourable condition of such spaces for social contacts.

The use of neighbourhood public space is changing with the changing provision. The study has revealed that accessibility is one of the major issues with the use of the existing public spaces in the new neighbourhoods. Several public spaces in the study areas, particularly in the GRA, are not open to the residents on a daily basis. Those public spaces that are accessible are not inviting due to their inconvenient locations, the lack of elements of interest and the lack of regular maintenance. Consequently, the changes are noticed in the daily use of public space which has been confined to a very few activities. Some neighbourhood public spaces are not useable because these have been leased out to private parties for financial returns, and thus, are not accessible to the residents around the clock, but controlled by those who operate them. This supports the views made by Carr et al. (1992) on potential disadvantages of the increasing private control of public space. Gehl (1987) suggests that optional activities in public space take place when there is a favourable physical condition. However, the current situation of public space has led to the decreasing level of optional activities taking place on a daily basis in the new neighbourhoods. It appears that the effective use of public space can now be seen only during neighbourhood events. This highlights a shifting pattern in the nature of public activities.

Along with the nature, the locations of public activities are also shifting. Since most residents primarily use streets as a public space, there is a growing role of neighbourhood streets as a social and recreational space. Apparently, the streets are more accessible to the residents than the planned open spaces, despite the lack of social quality (or maintenance), and the residents seem to have adapted to the unsupportive environment of the neighbourhood streets to use them for social contacts and activities. While the streets have been traditionally used for public activities (Hosken 1974), the residents of the new neighbourhoods have been forced to do so, due to the loss open spaces. These streets and the associated semi - public spaces such as the shop fronts of local cafés and grocery stores are venues for a range of neighbourhood activities, particularly those 
performed on a daily basis. On the other hand, findings also suggest that a large portion of neighbourhood life now also takes place in privately owned public spaces. The case of the GRA and BT reveals that the local cafés and restaurants are increasingly being used as a social space on a daily basis as well as during neighbourhood social events.

The changing provision and use of neighbourhood public space poses significant challenges in the management of contemporary urban development in the Kathmandu Valley. The overall loss of public space in the new neighbourhoods suggests that governance and regulations have been ineffective to regulate rapid urban growth. While the growing neighbourhoods have failed to appreciate the role of public space, the poor development of neighbourhood public space is already affecting the quality of social life, with declining participation of the residents in the public realm. Residents' neighbourhood social life may not always take place in privately owned public spaces in the Nepalese context. Consequently, the level of social contact and interaction among them is decreasing, and their social wellbeing has been compromised in many cases, with a potentially adverse effect on the sense of community. All these consequences indicate that sustainability of social life may emerge as a major challenge of the current transformation of public space in the new neighbourhoods. Maintaining the quality of neighbourhood life thus becomes imperative, which is possible through a better provision and use of public space. Future urban development policies and plans for the Kathmandu Valley should consider this need and endeavour to develop neighbourhood public space as a critical urban amenity. Furthermore, the shifting pattern of public activities and their locations suggest that there is a need to consider the changing nature and characteristics of the contemporary public spaces in terms of their responsiveness to the changing context and needs.

\section{References}

Adhikari, A. P. 1998. Urban and environmental planning in Nepal - analysis, policies and proposals. Kathmandu: The World Conservation Union (IUCN).

Banerjee, T. 2001. The future of public space, Journal of the American Planning Association 67: 9-24. https://doi.org/10.1080/01944360108976352

Basyal, G. K.; Khanal, N. R. 2001. Process and characteristics of urbanization in Nepal, Contribution to Nepalese Studies 28: $187-225$.

Carmona, M.; Tiesdell, S.; Heath, T.; Oc, T. 2010. Public places urban spaces: the dimensions of urban design. London: Architectural Press.
Carr, S.; Francis, M.; Rivlin, L. G.; Stone, A. M. 1992. Public space. Cambridge: Cambridge University Press.

Chitrakar, R. M. 2006. A study of historic urban squares of Kathmandu Valley: defining contemporary public open space design: Master of Urban Design Dissertation. The University of Hong Kong.

Chitrakar, R. M.; Baker, D.; Guaralda, M. 2014. Urban growth in the Kathmandu Valley: the transformation of public space, in Past Present and Future of Public Space - International Conference on Art, Architecture and Urban Design, 25-27 June 2014, Bologna, Italy.

Chitrakar, R. M.; Baker, D. C.; Guaralda, M. 2016. Urban growth and development of contemporary neighbourhood public space in Kathmandu Valley, Nepal, Habitat International 53: 30-38. https://doi.org/10.1016/j.habitatint.2015.11.006

Ellin, N. 1996. Postmodern urbanism. Cambridge, MA: Blackwell.

Gehl, J. 1987. Life between buildings: using public space. New York: Van Nostrand Reinhold.

Gutschow, N.; Kolver, B. 1975. Ordered space concepts and functions in a town of Nepal: Bhaktapur. Baden: KommissionsVerlag Franz Steiner.

His Majesty's Government of Nepal 1988. Town Development Act. Kathmandu.

Hosken, F. P. 1974. The Kathmandu Valley towns: a record of life and change in Nepal. New York: Weatherhill.

ICIMOD, UNEP \& Government of Nepal 2007. Kathmandu Valley Environment Outlook. Kathmandu: ICIMOD.

Jacobs, J. 1961. The death and life of Great American Cities. New York: Random House.

KMC/WORLD BANK 2001. City diagnostic report for city development strategy: Kathmandu Metropolitan City. Kathmandu: Kathmandu Metropolitan City/World Bank.

KVTDC 2007. Building By-laws for the Kathmandu Valley. Kathmandu: Kathmandu Valley Town Development Committee.

Madanipour, A. 1996. Design of urban space: an inquiry into a socio-spatial process. Chichester: John Wiley.

Madanipour, A. 1999. Why are the design and development of public spaces significant for cities?, Environment and Planning B: Planning and Design 26: 879-891. https://doi.org/10.1068/b260879

Madanipour, A. 2003. Public and private spaces of the city. London, New York: Routledge.

Madanipour, A. (Ed.) 2010. Whose public space? International case studies in urban design and development. Abingdon, Oxon, New York: Routledge.

Oldenburg, R. 1989. The great good place: cafés, coffee shops, bookstores, bars, hair salons, and other hangouts at the heart of a community. New York: Marlowe \& Company.

Orum, A. M.; Neal, Z. P. 2009. Common ground? Readings and reflections on public space. 1 ed. Hoboken: Taylor \& Francis.

Pant, M.; Fune, S. 2007. Stupa and Swastika: historical urban planning principles in Nepal's Kathmandu Valley. Kyoto, Singapore: Kyoto University Press in association with NUS Press.

Pradhan, M. G. 2003. Urban open spaces in Kathmandu - problems and prospects, Vaastu 5: 45-46.

Sennett, R. 1986. The Fall of Public Man. London: Faber. 
Shah, B.; Pant, D. 2005. Transformation of urban structures in the Kathmandu Valley, in International Conference for Integrating Urban Knowledge \& Practice, 29 May - 4 June 2005, Gothenburg, Sweden.

Sharma, B. 2006. Fast disappearing open spaces (de facto lungs) of Kathmandu Valley, Scitech Nepal 9: 30-33.

Shokoohy, M. 1994. Urban fabric, in M. Shokoohy, N. H. Shokoohy (Eds.). Kirtipur: an urban community in Nepal - its people, town planning, architecture and arts. London: Araxus Books.

Shrestha, B. K. 2005. How not to design a neighbourhood reviewing different residential precincts of Kathmandu, Scitech Nepal 8: 46-69.

Shrestha, B. K. 2010. Housing provision in the Kathmandu Valley: public agency and private sector initiation, Urbani Izziv 21: 85-95. https://doi.org/10.5379/urbani-izziv-en-2010-21-02-002

Shrestha, B. K.; Shrestha, S. 2006. To whom it may concern privatization of public spaces: a case of Dharahara Sundhara Square, Kathmandu, Scitech Nepal 9: 3-22.

Shrestha, V. 2001. Sustainable urban housing in Kathmandu, Nepal: proposals and evaluations: $\mathrm{PhD}$ Thesis. University of California, Los Angeles.

Thapa, R. B.; Murayama, Y.; Ale, S. 2008. Kathmandu, Cities 25: 45-57. https://doi.org/10.1016/j.cities.2007.10.001

Tibbalds, F. 2001. Making people friendly towns: improving the public environment in towns and cities. London: Spon Press.

Tiwari, S. R. 1989. Tiered temples of Nepal, Kathmandu: Sunita Tiwari.

Tiwari, S. R. n.d. City space and life then, 150 years ago - a presentation of concept and realities [online], [cited 26 April 2012]. Available from Internet: http://www.kailashkut.com/ pagepublications/cityspaceandlife.pdf

Trancik, R. 1986. Finding lost space: theories of urban design. New York: John Wiley.

Wirth, L. 1938. Urbanism as a way of life, American Journal of Sociology 44: 1-24. https://doi.org/10.1086/217913

Worpole, K.; Knox, K. 2007. The social value of public spaces. London: Joseph Rowntree Foundation.

\section{RAJJAN MAN CHITRAKAR}

Dr. Rajjan Man Chitrakar currently works as a Sessional Academic in the School of Design at the Queensland University of Technology, Brisbane, Australia, where he teaches urban design and research methods. His research interests are situated at the intersection of urban design and planning and focuses on urban growth and change, provision, use and management of public space, place making, sustainable development of urban neighbourhoods, community resilience and sense of community. Dr. Chitrakar is a highly motivated and enthusiastic academic with significant teaching, research and industry experience in architecture, urban design and planning in Australia and overseas.

\section{DOUGLAS C. BAKER}

Dr. Douglas C. Baker is Professor and Head of Property and Planning in the School of Civil Engineering and the Built Environment at the Queensland University of Technology. Dr. Baker's areas of expertise include land use planning, performance-based measurement, airport management, and regional governance. He has worked in the public and private sectors, and prior coming to Australia he worked in the School of Environmental Planning at the University of Northern British Columbia.

\section{MIRKO GUARALDA}

Dr. Mirko Guaralda is Senior Lecturer in Architecture at the Queensland University of Technology. He is currently Research Ethics Advisor for the Creative Industries Faculty. Dr. Guaralda's background includes experience in architectural design, landscape architecture and urban design. His research focuses on people-place interaction and analyses cityscapes through the identification of recurrent patterns, building typologies and design principles. The identity and character of a site are interpreted also analysing lived experiences and uses of the built environment. Dr. Guaralda's research aims to provide a better understanding of urban dynamics, at different scales, to support a positive development and/or management of our cities. 